\title{
FACTORS AFFECTING LONG-TERM COOPERATION WITH LOGISTICS SERVICE PROVIDERS
}

Aleksandrs Kotlars ${ }^{1}$, Mg.oec; Inguna Jurgelane-Kaldava², assoc.professor/ Dr.oec. and Valerijs Skribans ${ }^{3}$, assoc.professor/ Dr.oec.

\section{1, 2, 3 Riga Technical University, Latvia}

\begin{abstract}
Nowadays different approaches are used by the companies to systematically compare and evaluate logistics service providers. The purpose of this study is to define and classify requirements, evaluation criteria and quality criteria set towards logistics service providers. In this study, information is gathered about the selection arrangements for logistics providers, which were collected from several companies. Authors looked for information related to the following questions: what are the criteria for evaluating logistics service providers; what are the requirements that logistics providers need to ensure to become a partner; what are the objectives of the selection contests (procurement tenders) defined by the companies; what are the main service quality indicators that are used to measure the performance of logistics service providers. Companies originated in the European Union from various countries have been examined. A literature review was conducted that helped to collect information regarding application of multiple-criteria decisionmaking for selection of logistics service providers and extract proposed selection criteria. Analysis of procurement documentation by logistics service providers was done to extract and group data that will be used to develop decisionmaking framework in further research. Authors created unique groups of logistics service providers selection criteria, requirements towards logistics service providers, selection goals and key performance indicators. Finally, general market research of pre-defined industries was made. There are very few studies dedicated to selection of criteria and requirements towards logistics service providers. Companies tend to formulate selection criteria of logistics service providers in general manner, at the same time, not paying attention to formulating selection process goals.
\end{abstract}

Key words: logistics service providers, procurement, evaluation factors.

JEL code: L90, M16, R40, R41

\section{Introduction}

The aim of this study is to collect and classify information related to logistics service provider selection.

Collected information to be divided in following groups:

- logistics service provider selection criteria;

- requirements set by companies towards logistics service providers;

- companies' goals of the selection process;

- logistics service providers' key performance indicators of service quality.

The main tasks of this study are:

- to collect procurement documentation and data related to selection of logistics service providers;

- to extract specific information about the evaluation and selection of logistics service providers by analysing procurement documentation;

- to structure extracted information by performing word coding and create unique groups;

- to make conclusions regarding logistics service providers selection process.

The data were collected from tender documentation issued by selected companies. Standard logistics service providers selection process consists of following steps.

1) Analysis of company's needs.

2) Definition of the goal of selection process.

3) Establishing evaluation expert team. 

4) Definition of evaluation criteria.
5) Primary market screening.
6) Primary filtering of logistics service providers.
7) Request for quotation.
8) Evaluation of submitted commercial offers.
9) Selection and contracting logistics service providers.
10) Monitoring of results and improvement of process.

As the result of activities starting from analysis of company's needs until primary filtering of logistics service provider, a set of documentation is prepared that is issued to potential logistics service providers in scope of request for quotation (step 7). This set normally includes general terms and conditions, standard operating procedure, planning procedure, site or warehouse specification, description of products, invitation letter, set of key performance indicators, statistical database (e.g. historical shipments), price template (template of commercial offer) and other specific information needed to describe service request. Authors of this study used these sets of documentation to extract essential information needed to answer four questions defined in scope of this study.

- What are the criteria for evaluating and selecting logistics service providers?

- What are the requirements that logistics providers need to correspond to become a partner?

- What are the goals of the selection process (procurement tenders) defined by the companies?

- What are the main service quality key performance indicators that measure the performance of logistics service providers?

Companies from 17 European Union countries with regional or central logistics purchasing teams and decision-makers were examined. Figure 1 shows number of companies per country choses for this study.

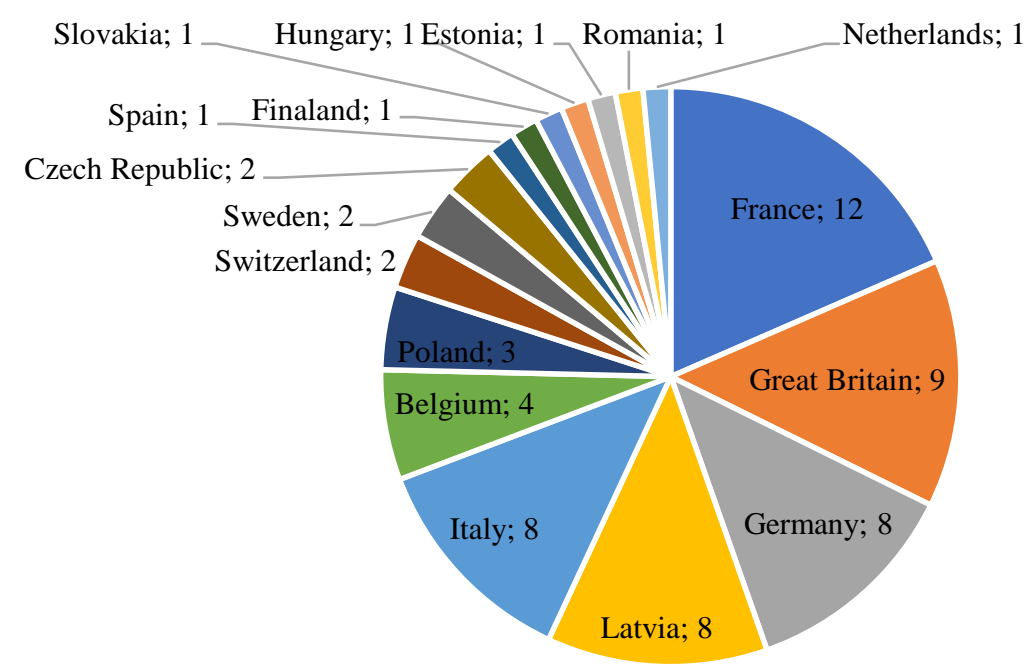

\section{Source: made by authors based on analysis of companies' documentation}

\section{Fig. 1. Summary of analysed companies per country}

Analysis was conducted by studying tender documentation issued by the companies in 2018, 2019 and 2020. In total, 65 companies were selected, analysed, and divided into 3 groups.

First group companies - Producers of electrical equipment (NACE Rev. 2, group 27).

Second group companies - Wholesale and retail companies, food producers (NACE Rev. 2, groups 46, 47 and 10$)$. 
Third group companies - Producers of basic pharmaceutical substances and pharmaceutical preparations (NACE Rev. 2, group 21).

\section{Methodology}

While analysing documentation and data related to the evaluation and selection of logistics service providers, authors of this study looked for information, according to four pre-defined questions. The approach of analysis is shown in Figure 2.

\section{Research questions $(1-4)$}

\begin{tabular}{|c|c|c|c|}
\hline $\begin{array}{l}\text { Documentation set } \\
\text { from companies } \\
(1-65)\end{array}$ & $\begin{array}{l}\text { Statements on } \\
\text { research question } \\
(1-n)\end{array}$ & $\begin{array}{l}\text { Keywords extracted } \\
\text { from statements } \\
(1-n)\end{array}$ & Unique groups \\
\hline
\end{tabular}

Source: made by authors based on analysis of companies' documentation

\section{Fig. 2. Description of documentation research approach}

The information from set of documentation was collected (statements on research question) and sorted by specific keywords, using coding method. As a result of coding, individual groups of keywords were formed that combine multiple sentences, or statements about a given question.

As a next step, the results of the research (keywords) are evaluated according to the previously defined questions. For each of four pre-defined question, a summary of results is compiled for all 65 selected companies in general and by groups of companies (3 groups).

The coding revealed that the company, when defining the answers to the questions on the evaluation and selection criteria, the requirements towards logistics service providers, the tender goals, and the quality key performance indicators, makes several statements which, in essence, express similar idea. For example, company makes the following statements about the evaluation criteria: "Environment, health and safety policy and practices..." or "Active attitude towards environmental issues...". Both above statements are included in the group "environmental policy" and counted twice.

Knowing that one company can make ideologically similar statements in response to a single question several times (intentionally or unintentionally), the task is to understand the idea of statement (formulation), consider and count all mentioning, and estimate relative number of mentioning.

\section{Literature review}

Logistics service provider selection is a multi-criteria problem, so consequently, a complex process where multiple (both tangible and intangible) criteria need to be taken into account. Some criteria are developed according to specific customer needs while others are common for all circumstances. Conducted literature review shows that few attentions are paid specifically to these criteria (how these criteria a developed according to company's needs).

There are various studies dedicated to logistics service provider selection, as a multi-criteria decisionmaking problem. Aguezzoul (2014) proposed 5 main categories classifying methods for selection of logistics service providers, incl. various techniques of multi-attribute decision-making (MCDM); statistical approaches; artificial intelligence techniques; mathematical programming models; and integrated approaches. Govindan et al. (2015) proposed classifying selection methods according to 3 main categories, incl. multi-criteria decision-making according to individual methodology; multi-criteria decision-making according to integrated methodology; and environmental criteria-based supplier selection. Ho et al. (2010) 
proposed classifying selection methods according to 2 main categories with several sub-categories, incl. individual approaches and integrated approaches (combination of various methods). Several authors (Tavana et al. (2016); Prakash et al. (2016); Jung (2017); Bianchini (2018); Jovcic (2019); Ozcan (2020) emphasize importance of choosing correct method to evaluate selection criteria and determine importance of these criteria. There are several studies dedicated to measurement of key performance indicators of logistics service providers. Chia et al. (2009) examined how senior supply chain executives perceive performance measurement from a balanced scorecard perspective. Jothimani et al. (2014) explored the applicability of the supply chain operations reference model and identified the key performance indicators for the logistics service providers. Krauth et al. (2005) examined performance parameters and objectives that play a role in the planning process of logistics service providers.

\section{Logistics service providers selection criteria}

Figure 3 summarizes the results on the evaluation and selection criteria for logistics service providers. As a result of the analysis, companies' statements about the evaluation criteria of logistics service providers are divided into 16 unique groups. Relative number of mentioning within the groups is shown in this figure. Total number of mentioning within groups - 143. Explanation of these statements is provided below.

Reliability of the commercial offer

Price level

Key account management Acceptance of contractual conditions

Service execution time Capacity of the company

Industry experience Past collaboration experience

Environmental policy

Financial stability of the company

Flexible solution, adjustment capabilities

Geographical coverage

Certification

IT support

Innovative solution

Shipment tracking capabilities

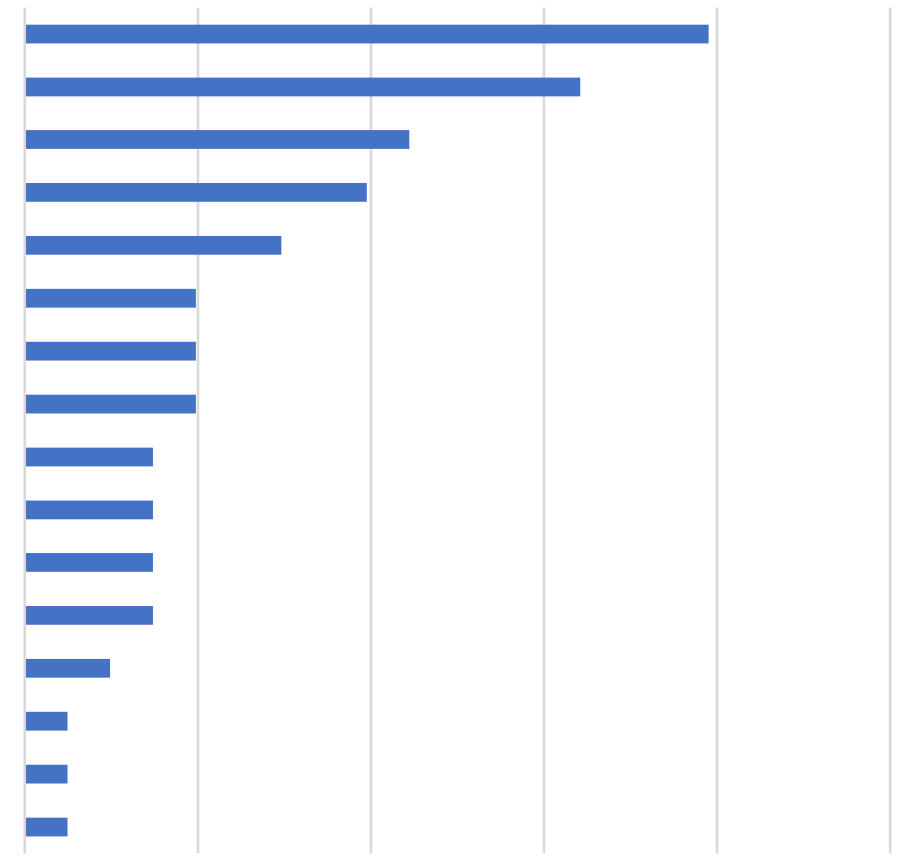

$$
0,00 \% \quad 5,00 \% \quad 10,00 \% \quad 15,00 \% \quad 20,00 \% \quad 25,00 \%
$$

\section{Source: made by authors based on analysis of companies' documentation}

\section{Fig. 3. Logistics service providers selection criteria}

The dominant evaluation criterion is reliability of the commercial offer ( $19.75 \%$ of total mentioning). There are different statements included in this group. The common sign among all those statements is related to reliability of the offer placed by logistics service provider in various meanings. Following statements can be mentioned as example: "Do not quote for lanes unless you are prepared to undertake them...", "The highest standards of customer service and reliability...". Second evaluation criterion is price level ( $16.05 \%$ of total mentioning). Third evaluation criterion is key account management (11.11\% of total mentioning). It includes such statements as "Service level commitment by logistics service provider...", "Availability of control tower...". 
Looking at evaluation criteria set by companies from various industries, some differences may be noticed. First group companies (Producers of electrical equipment) prioritize acceptance of contractual conditions (20.8\% of total mentioning), followed by key account management (18.8 \% of total mentioning) and reliability of the commercial offer (12.2\% of total mentioning). Second group companies (Wholesale and retail companies, food producers) prioritize price level (20.0\% of total mentioning), followed by reliability of the commercial offer ( $18.8 \%$ of total mentioning) and financial stability of the company (12.5\% of total mentioning). Third group companies (Producers of basic pharmaceutical substances and pharmaceutical preparations) prioritize reliability of the commercial offer ( $22.8 \%$ of total mentioning), followed by price level $(12,7 \%$ of total mentioning) and key account management ( $11.4 \%$ of total mentioning).

\section{Requirements towards logistics service providers}

Figure 4 summarizes the results of requirements set by companies towards logistics service providers. As a result of the analysis, companies' statements about the requirements towards logistics service providers are divided into 9 unique groups. Relative number of mentioning within the groups is shown in this figure. Total number of mentioning within groups - 110. Explanation of these statements is provided below.

Offer correspondence to contractual conditions

Personnel capacity and quality assurance

Correspondance to safety measures

Provision of customer service

Respect for service capacity

Compliance of the service with the norms of the Law

Flexibility, capacity to provide additional solutions

Non-variability of costs during the contract

Compliance with the time of service execution

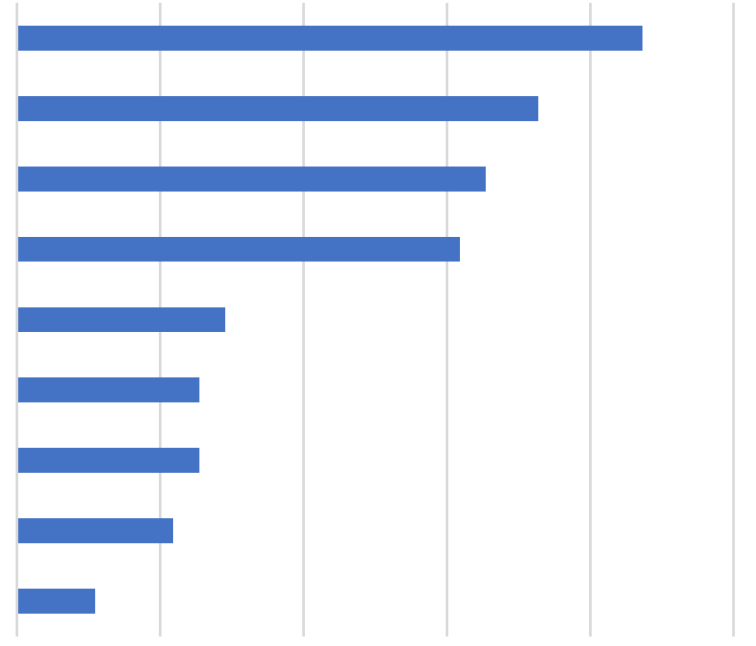

$0,00 \% \quad 5,00 \% \quad 10,00 \% \quad 15,00 \% \quad 20,00 \% \quad 25,00 \%$

\section{Source: made by authors based on analysis of companies' documentation}

\section{Fig. 4. Requirements towards logistics service providers}

The dominant requirement towards logistic service providers is ability to offer correspondence to contractual conditions ( $21.82 \%$ of total mentioning). There are various statements included in this group. The common sign among all those statements is related to willingness of logistics service provider to accept contractual conditions set by the company. Following statements can be mentioned as example: "Compliance with payment terms...", "High standards of service relating to on-time and in-quality deliveries...", "Acceptance of payment terms...". Second requirement towards logistic service providers is personnel capacity and quality assurance (18.18\% of total mentioning). Following statements can be mentioned as example: "The logistics service provider ensures availability by providing a 24-hour on-call emergency number...". Third requirement towards logistic service providers is correspondence to safety measures ( $16.36 \%$ of total mentioning). It includes such statements as "Equipment used by the carrier must be in good technical condition and fulfil the necessary requirements for safe and effective execution of transport ...". 
When looking at requirement towards logistic service providers in industry cross-sections, priority among companies representing different industries varies. First group companies prioritize provision of customer service (36.4\% of total mentioning), followed by offer correspondence to contractual conditions ( $18.2 \%$ of total mentioning) and non-variability of costs during the contract ( $9.1 \%$ of total mentioning). Second group companies prioritize correspondence to safety measures (23.1\% of total mentioning), followed by personnel capacity and quality assurance (15.4\% of total mentioning) and compliance of the service with the norms of Law ( $15.4 \%$ of total mentioning). Third group companies prioritize ability to offer correspondence to contractual conditions (24.7\% of total mentioning), followed by personnel capacity and quality assurance (19.2\% of total mentioning) and correspondence to safety measures (16.4\% of total mentioning).

\section{Goals of the selection process}

Figure 5 summarizes the results of goal definition for selection of logistics service providers. As a result of the analysis, companies' statements about the evaluation criteria of logistics service providers are divided into 10 unique groups. Relative number of mentioning within the groups is shown in this figure. Total number of mentioning within groups -65 . Explanation of these statements is provided below.

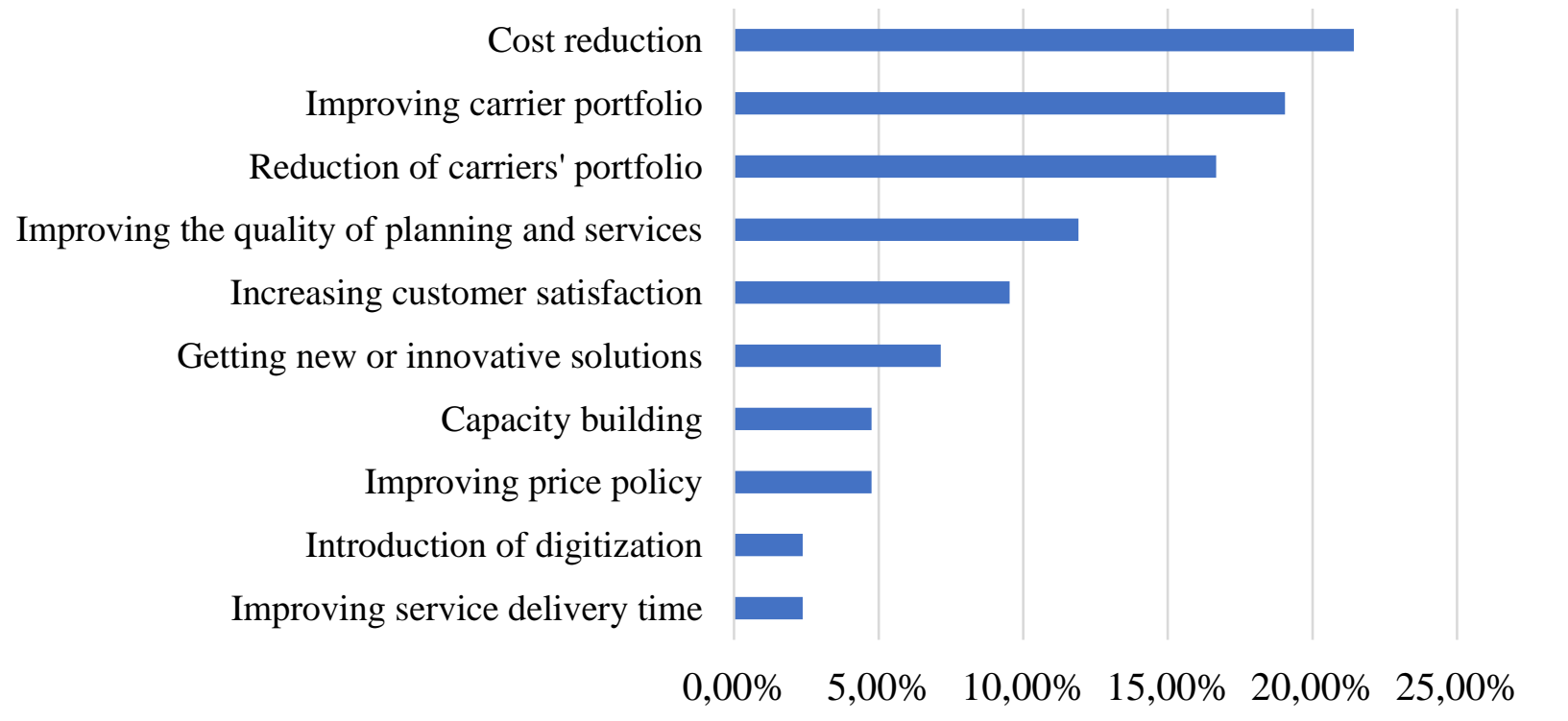

\section{Source: made by authors based on analysis of companies' documentation}

\section{Fig. 5. Goals of the selection process}

The dominant goal of selection of logistic service providers is cost reduction (21.43\% of total mentioning). Second popular goal for selection of logistics service providers is improving carrier portfolio ( $10.05 \%$ of total mentioning). Following statements can be mentioned as example: "The goal is to ease the adaptation of the logistics service...", "Formalize supplier management...". In general, portfolio improvement activities mean improvement of portfolio management, for example revision of conditions, structuring, prioritizing of carriers. Third requirement towards logistic service providers is reduction of carriers' portfolio (16.67\% of total mentioning). Study shows that portfolio consolidation approach is clearly set nowadays, as companies tend manage smaller number of carriers.

When looking at goal of selection of logistic service providers in industry cross-sections, priority among companies representing different industries differs. First group companies prioritize improving carrier portfolio (33.3\% of total mentioning), followed by cost reduction ( $22.2 \%$ of total mentioning) and improving price policy ( $11.1 \%$ of total mentioning). Following statements can be mentioned as example 
of improving price policy: "Company is seeking competitive and sustainable rate structure...". Second group companies prioritize cost reduction and improving the quality of planning and services (both goals have $28.6 \%$ of total mentioning), followed by increasing customer satisfaction (14.3\% of total mentioning). Third group companies prioritize cost reduction and reduction of carriers' portfolio (both goals have $19.2 \%$ of total mentioning), followed by improving carrier portfolio.

\section{Key performance indicators of service quality}

Figure 6 summarizes key performance indicators of service quality used by companies to evaluate logistics service providers. As a result of the analysis, companies' statements about the evaluation criteria of logistics service providers are divided into 10 unique groups. Relative number of mentioning within the groups is shown in this figure. Total number of mentioning within groups - 68. Explanation of these statements is be provided below.

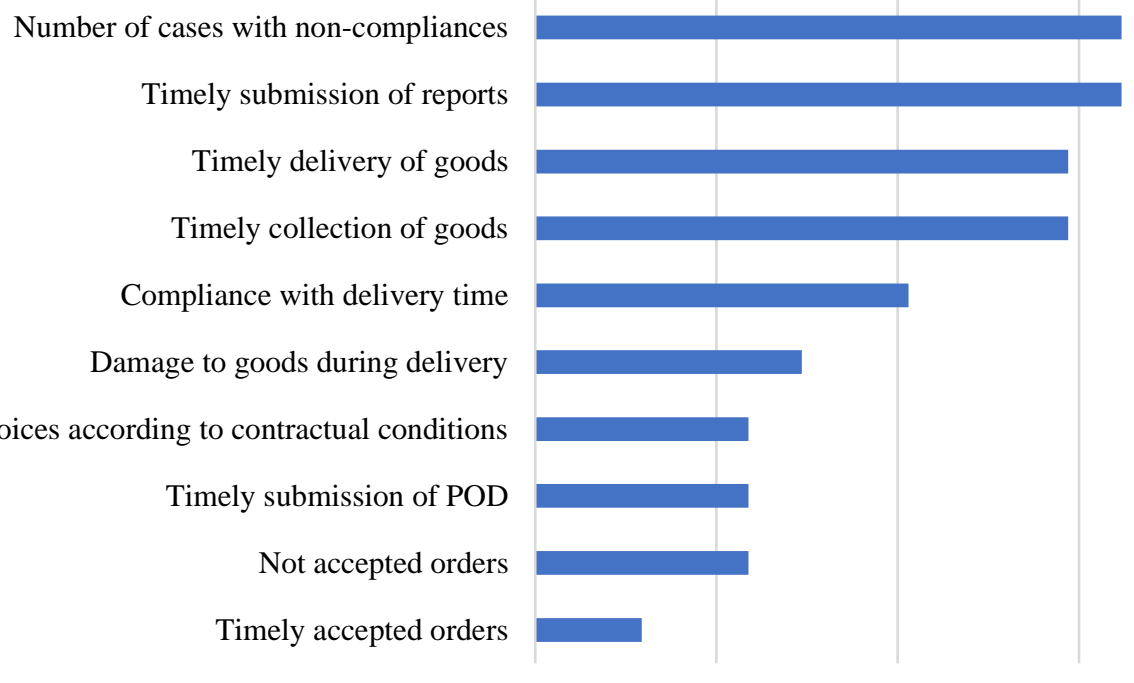

$$
0,00 \% \quad 5,00 \% \quad 10,00 \% \quad 15,00 \% \quad 20,00 \%
$$

\section{Source: made by authors based on analysis of companies' documentation}

\section{Fig. 6. Key performance indicators of service quality}

The dominant key performance indicators (KPI) used to evaluate logistics service providers are number of cases with non-compliances (both have $16.18 \%$ of total mentioning) and timely submission of reports (16.18\% of total mentioning). Subsequent widely used KPI are timely delivery of goods and timely collection of goods (both have $14,71 \%$ of total mentioning). When looking at KPI in industry cross-sections, first group companies prioritize timely delivery of goods and timely submission of reports (both have $18.2 \%$ of total mentioning). Second group companies prioritize timely collection of goods and timely delivery of goods (both have $21.4 \%$ of total mentioning). Third group companies prioritize number of cases with noncompliances ( $20.9 \%$ of total mentioning), followed by timely submission of reports (16.3\% of total mentioning) and compliance with delivery time (11.6\% of total mentioning).

\section{Conclusions, proposals, recommendations}

1) According to conducted literature review, it was discovered, that many studies were performed describing process of logistics service provider selection itself. Main emphasis is put on methodology and splitting selection process into sub-processes. At the same time, correctness of selection is crucially dependant on input data. Correct definition of selection criteria, goal of the selection process and requirements towards logistics service providers is a vital part of multiple-criteria decision making. 
Definition of selection criteria is a preparatory stage before building a selection framework and it is advisable to study this topic deeper.

2) As a result of tender documentation studies, it was discovered that many companies formulate various logistics service providers' selection criteria, which in fact are very similar. It is advisable to include different (by meaning) selection criteria in tender documentation, that would help integrating these criteria into framework of selection process and access logistics service providers from different angles.

3) As a result of the study, there were created 16 unique groups of logistics service providers selection criteria, 9 unique groups of requirements towards logistics service providers, 10 unique groups of goals of the selection process, and 10 unique groups of key performance indicators of service quality.

4) As a result of tender documentation studies, it was discovered that companies do not pay attention to formulating selection process goals and at the same time, create various selection criteria and requirements towards logistics service providers. Setting the right goal is a basis of selection process that guides companies through entire process towards right choice of logistics service provider.

5) As a result of tender documentation studies, differences of priorities (selection criteria, requirements etc.) among representatives of different industries were discovered. This fact emphasizes the importance of creating individual selection framework for particular industry.

\section{Bibliography}

1. Aguezzoul, A. (2014). Third-party Logistics Selection Problem: A Literature Review on Criteria and Methods. Omega (United Kingdom), 49, 69-78. DOI:10.1016/j.omega.2014.05.009

2. Bianchini, A. (2018). 3PL Provider Selection by AHP and TOPSIS Methodology. Benchmarking, 25(1), $235-252$. DOI: $10.1108 / \mathrm{BIJ}-08-2016-0125$

3. Chia, A., Goh, M., Hum, S. -. (2009). Performance Measurement in Supply Chain Entities: Balanced Scorecard Perspective. Benchmarking, 16(5), 605-620. DOI:10.1108/14635770910987832

4. Govindan, K., Rajendran, S., Sarkis, J., Murugesan, P. (2015). Multi Criteria Decision Making Approaches for Green Supplier Evaluation and Selection: A literature Review. Journal of Cleaner Production, 98, 66-83. DOI: $10.1016 / j$.jclepro.2013.06.046

5. Ho, W., Xu, X., Dey, P. K. (2010). Multi-criteria Decision Making Approaches for Supplier Evaluation and Selection: A literature Review. European Journal of Operational Research, 202(1), 16-24. DOI: $10.1016 /$ j.ejor.2009.05.009

6. Jothimani, D., Sarmah, S. P. (2014). Supply Chain Performance Measurement for Third Party Logistics. Benchmarking, 21(6), 944-963. DOI:10.1108/BIJ-09-2012-0064

7. Jovcic, S., Prusa, P., Dobrodolac, M., Svadlenka, L. (2019). A Proposal for a Decision-making Tool in Third-party Logistics (3PL) Provider Selection Based on Multi-criteria Analysis and the Fuzzy Approach. Sustainability (Switzerland), 11(15) DOI:10.3390/su11154236

8. Jung, H. (2017). Evaluation of Third Party Logistics Providers Considering Social Sustainability. Sustainability (Switzerland), 9(5) DOI:10.3390/su9050777

9. Krauth, E., Moonen, H., Popova, V., Schut, M. (2005). Performance Measurement and Control in Logistics Service Providing. Paper presented at the ICEIS 2005 - Proceedings of the 7th International Conference on Enterprise Information Systems, 239-247.

10. Ozcan, E., Ahiskali, M. (2020). 3PL Service Provider Selection with a Goal Programming Model Supported with Multicriteria Decision Making Approaches. Gazi University Journal of Science, 33(2), 413-427. DOI: $10.35378 /$ gujs. 552070

11. Prakash, C., Barua, M. K. (2016). An Analysis of Integrated Robust Hybrid Model for Third-party Reverse Logistics Partner Selection Under Fuzzy Environment. Resources, Conservation and Recycling, 108, 63-81. DOI: 10.1016/j.resconrec.2015.12.011

12. Tavana, M., Zareinejad, M., Di Caprio, D., Kaviani, M. A. (2016). An Integrated Intuitionistic Fuzzy AHP and SWOT Method for Outsourcing Reverse Logistics. Applied Soft Computing Journal, 40, 544-557. DOI: $10.1016 /$ j.asoc. 2015.12 .005 